\title{
Framing as strategy for effective communication about Fair Trade products in Flanders
}

\author{
Ewout Stoefs ${ }^{1}$ and Erik Mathijs ${ }^{2, *}$ \\ ${ }^{1}$ The Federal Public Service Foreign Affairs, Foreign Trade and Development Cooperation, Karmelietenstraat 15, 1000, \\ Brussels; and ${ }^{2}$ Department of Earth and Environmental Sciences, Katholieke Universiteit Leuven, Celestijnenlaan 200, \\ E - 2411, 3001 Leuven, Belgium
}

\begin{abstract}
This paper investigates whether reframing an issue related to sustainable consumption can influence citizens' attitude towards that issue. Our investigation focuses on the case of Fair Trade in Flanders, Belgium. Fair Trade contributes to sustainable development by offering better conditions to marginalized producers in the South. Using an internet-based experimental setup, 1617 individuals were exposed to an NGO-based frame, a retailer-based frame, an experimental frame or no frame. Statistical analysis then indicated whether the experimental frame performed better than the control group and the other frames in shifting people's attitudes. Our results suggest that a brief exposure to a combination of tone, messenger, value and metaphor that signals the systemic aspects of Fair Trade may be successful in shifting the attitude and opinion of Flemish consumers/citizens in favour of Fair Trade. Our analysis suggests that the foundations metaphor that has been developed in the context of the environmental impact of food production can also be applied in the context of the social impact of food production.
\end{abstract}

Keywords: communication, Fair Trade, framing

\section{Introduction}

Changing consumer behaviour towards more sustainability is not an easy task. In his comprehensive overview of the literature on consumer behaviour and behavioural change, Jackson (2005, p. 119) concludes that 'overcoming problems of consumer lock-in, unfreezing old habits and forming new ones, understanding the complexity of the social logic in which individual behaviours are embedded: all these are pre-requisites for successful behaviour change initiatives'.

An important barrier against changing consumer behaviour is that consumers use routines and habits

*Corresponding author. Email: erik.mathijs@ees.kuleuven.be where their involvement in the purchasing of goods is low. Recent research highlights that individuals use mental short cuts to provide meaning to their choices as a consumer, but also as a citizen (Aubrun et al., 2005, 2006). These mental models tend to be derived from a dominant discourse or dominant frame in society that is reinforced by both commercial and non-commercial communication messages. Changing this dominant discourse by reframing communication is therefore an interesting avenue for changing individuals' attitudes towards more sustainable consumption and policy practices.

The purpose of this paper is to investigate whether reframing an issue related to sustainable consumption can influence citizens' attitudes 
towards that issue. Our investigation focuses on the case of Fair Trade in Flanders, Belgium. We consider sustainability as a broader concept encompassing three interdependent dimensions - that is, economic, ecological and social dimensions (Mebratu, 1998). This approach has also been adopted to evaluate agricultural sustainability by, for example, Van Calker et al. (2006) and Van Cauwenbergh et al. (2007). We thus consider Fair Trade as part of the concept of sustainability (see also Strong, 1998). Fair Trade may contribute to sustainable development by offering farmers in the South a guaranteed minimum price - contributing to the economic dimension of sustainability - and a premium that is invested in social and environmental projects selected by Fair Trade producer cooperatives or worker organizations (Strong, 1998; Raynolds, 2000). While Fair Trade sales are rising sharply worldwide, it still accounts for only 0.05 per cent of the total retail market in Belgium (IDEA Consult, 2007).

This paper will test the effect of alternative discourses on the attitude of individuals towards policies and actions favouring Fair Trade by carrying out an internet survey. The remainder of the paper is organized as follows. The second section discusses the concept of framing and introduces the research question. Next is a section on data and methodology, followed by a discussion of the results of our analysis, and then a conclusion.

\section{Framing}

Framing is a concept that originates from cognitive psychology (Bartlett, 1932) and anthropology (Bateson, 1972), and which has been used later by other domains such as sociology (Goffman, 1974). As a result, frames and framing have different definitions and interpretations in different domains. In this paper, we consider the approach as proposed by Gilliam and Bales (2002) in their Strategic Frame Analysis ${ }^{\mathrm{TM}}$.

Strategic Frame Analysis ${ }^{\mathrm{TM}}$ identifies the dominant frames with which the public understands a certain issue, and then tries to develop and test the effect of reframes to change the public's way of thinking with respect to that issue. For this, the analysis takes into account the deeply established worldviews and generally accepted beliefs of people as well as the dynamic role the media play in creating and activating certain frames (Gilliam and Bales, 2002). Strategic Frame Analysis ${ }^{\mathrm{TM}}$ has been developed as an approach in communication research and practice to evaluate the effects of the different elements of a frame on support for policy measures, but it can also play an important role in influencing consumer behaviour. The effectiveness of communication messages can be increased (FrameWorks Institute, 2007) if the effect of a certain way of framing on consumer attitude is known. An analysis of frames assumes that people are not blank slates when they process new information. They link information they receive to what they already know or, as Lippmann wrote, 'We define first, and then we see' (Lippmann, 1921 , p. 44). In his analysis of public opinion he talks about stereotypes that are used by both the media and the public. As these stereotypes are the same, a pattern of expectations and assumptions emerges that keeps being reinforced. Gilliam and Bales (2002) call this the dominant frame. It forms a platform of ideas and beliefs from which people interpret new messages. When people get into contact with new information, they will compare that new information with the dominant frame. Kaplan and Kaplan (1982) talk about cognitive maps with which new information is categorized in our brains.

According to Gilliam and Bales (2002), framing is the way a story is being told. It is the selective use of images, metaphors, symbols and messengers and the way these signals incite our collective and sustainable cultural models. Frames are thus closely connected to the mental models or worldviews held by a certain culture. Characteristic of these mental models is that they are implicit and that they are difficult to change (Goffman, 1981; Van Gorp, 2007). In other words, attempts to change the dominant mental models or worldviews in a culture by reframing entail first challenging and then replacing those worldviews. Authors such as Kuhn (1962) and Yankelovich (1991) have written extensively about the difficulty of such paradigmatic shifts. This difficulty is rooted to a great extent in the dominance in our society of instrumental rationalist knowledge (Habermas, 1970, as cited by Bawden, 2005), such that in complex matters lay people do not think for themselves and largely 
accept the models imposed upon them by experts (Bawden, 2005).

Gilliam and Bales (2002) contend that the way a concept is being framed influences the way it is interpreted. Goffman (1974) describes framing in a similar way as an element of rhetoric that is packaged in a certain way as to allow certain interpretations and shun others. Framing can thus give way to a specific response. The way an issue is framed does not only influence the way we process information on that issue, but also how we think about that issue. Iyengar (1991) suggests that frames implicitly determine to whom or to what we attribute the responsibility of a problem. In this way frames also suggest potential solutions. However, rhetoric is not unknown to the field of environmental communication. We refer to Cox (2006) for a discussion of the significance of rhetoric in communicating for environmental change.

What does reframing imply in the case of sustainable consumption? Consumers use mental shortcuts - or what Giddens (1984) calls 'practical consciousness' - and will not always process all available product information when they are shopping. Many purchasing decisions are based on habits and routines without much conscious effort. Consumers simplify their decision making by using heuristics and rules of thumb. They use decision rules that allow them to derive certain product dimensions from others, such as for instance the assumption that more expensive products also have a higher quality (Solomon et al., 2006). Hence, consumer behaviour fits into the lack of reflexivity that characterizes our culture. What is needed is a trigger that challenges these mental models and that stimulates consumers to change their minds and develop new mental short cuts.

Aubrun et al. $(2005,2006)$ suggest that addressing individuals as consumers will not trigger individuals towards more sustainable food consumption. They suggest using metaphors that trigger the individual to think about the food system in a more systemic way. By systemic we mean insight into the various actors involved in agricultural and food production, the way they relate to each other and the impact they have on society and the environment. Therefore, our basic hypothesis here is that reframing Fair Trade using message elements that better communicate the systemic aspects of Fair Trade will result in a more positive attitude towards Fair Trade compared to messages used typically by an NGO or a retail chain.

\section{Data and methodology}

For our empirical investigation we collaborated with a large developmental NGO and a large retail chain. First, we investigated the frames that the retailer and the NGO are using in their communications when they talk about ethical consumption. Using this information we designed a representative message on Fair Trade for each organization that contains many of the elements that both organizations use in their communication strategies. Using insights from the USA, France and the UK (Aubrun \& Grady, 2006; Aubrun et al., 2005, 2006, 2007) we then reframed that message. Second, we carried out a large-scale internet survey to quantitatively test the impact of the different frames on consumer and citizen attitudes.

\section{Message design}

In November 2006, we carried out an in-depth analysis of the current frames used by both the retailer and the NGO to communicate about ethical consumption in general and Fair Trade in particular. For this, we used website information, recent publications and newspaper articles. In addition, we participated in editorial meetings and interviewed key persons in the marketing, communication, market research and design departments in both organizations to inquire about general communication strategies. Following this analysis, we constructed a representative message for each organization based on the dominant frame it uses and in consultation with the respective communication departments.

Key to our research is the dominant frame used in communication. Bales (2002) distinguishes six elements that may convey meaning and can be used to develop communication messages. These elements include:

- Context: contains the background information conveyed in a text. Context may stimulate a more systemic view of an issue and suggests 
both the cause of and who is responsible for a problem. Part of the context is making connections for the problem to fundamental values such as security, freedom, justice, etc.

- Numbers: may support a frame, but are not sufficient to create a frame. As most consumers apparently find that it is difficult to grasp the exact size and meaning of numbers, they need cues.

- Messengers: may amplify or undermine the message. Some messengers are more credible for some issues than others. In addition, messengers may also stimulate a more systemic view and may underline the severity of the problem.

- Visuals: may stimulate frames but can also undermine a verbal frame. Close-up images emphasize the personal and hide the ecological and the systemic.

- Simplifying models and metaphors: allow people to make inferences beyond the words used. As they contain mental models they may complete ways of thinking. They are easily picked up by the media.

- Tone: can be rhetorical, which tends to polarize people, or reasonable which makes people more open to scientific findings and practical solutions.

The three messages we constructed all deal with Fair Trade and suggest the improvement of the economic and social conditions of the farming households of the South. They have similar structure and length. Their discourse differs sufficiently, such that the Fair Trade story is told differently in each case. The messages differ in the core value they are based upon, in messenger and in tone. Note that these frames have been developed for experimental use and that they cannot be used as such in other contexts.

The retailer frame uses responsibility as its core value. Supermarket chains are the messenger. The tone of the message is relatively clinical and businesslike. In the NGO frame fairness was used as the core value and NGOs acted as messengers. As we sharpened the discourse of this message, its tone became more activist. The text also contains more context and facts as NGO communication aims at raising awareness. For the test frame we chose future generations as value, following the
US, UK and French framing research. Scientists are the messengers, following the recommendations of the FrameWorks Institute research. The French study concludes that the opinion of scientists is highly respected and their motives are not doubted. Other possible messengers include economists, politicians, experts, development workers, etc. Finally, we included the simplifying model suggested by FrameWorks, that is, the idea of a physical structure on which our food system is built. Specifically, we used the metaphors of supporting pillars.

The full text of the three messages is provided in Appendix 1. All messages were read and commented upon by the communication departments of both organizations and pretested with non-experts. We asked for feedback on readability, clarity, power of conviction, tone and credibility.

\section{Survey}

We designed a non-random internet survey to empirically test the impact of the different frames on consumer and citizen attitude towards buying Fair Trade and towards policies supporting farmers in the South. Respondents were randomly assigned to one of four groups: three groups were each given one of the three frames to read at the beginning of the questionnaire, while a fourth group did not receive an introductory text at all (control group). Respondents could access the questionnaire during one month (March 2007), during which they could win prizes such as movie tickets, books, etc. when they participated in the survey. An introduction mail was sent out to all Flemish universities and reached a significant number of students. The mail was also posted on various internet forums to invite other population groups, such as parents, the elderly, etc. to participate. Finally, a snowball technique was applied by asking respondents to forward the mail to 30 new contacts (here also they could win a prize).

While this is a relatively cost-efficient research method, the resulting sample is not representative for the Flemish population, as there is a bias towards university students. Therefore, we tested whether our results differed when considering students only vs. the total sample. Vermeir and Verbeke (2006) put forward three arguments for working with students. First, students are a 
relatively uniform group, where interference from socio-demographic variables such as age, income and social class is minimal. Second, young people are at the final phase of forming their identity and the development of their personal system of beliefs and values (Vermeir \& Verbeke, 2006). They are more open to change and any consumption changes made in this phase will be taken on in their later life. Third, it is more likely that highly educated youngsters already have some knowledge about Fair Trade. People who have no knowledge of Fair Trade are not able to answer questions related to intention and attitude.

\section{Questionnaire}

The questionnaire consisted of six parts (five for the control group). All questions were closed-ended. Where respondents had to give their opinion, a 7-point Likert scale was used (with the option of no opinion always present) ranging from strongly disagree (value 1) to strongly agree (value 7). A Likert scale is a way of measuring a respondent's attitude by asking him or her to what extent he or she agrees or disagrees with a statement.

First, respondents had to read the message and were asked to answer three questions (except for the control group). The first question asked to what extent respondents were familiar with the content of the message. The second question investigated the extent to which the message corresponds with the opinion of the respondent. The third question inquired into what extent the text is judged to be credible.

In a second set of questions, we inquired about the policy preferences of the respondents to investigate whether frames influence the attitude of the respondent as a citizen. First, respondents were asked to state their opinion as to what extent the following general policy interventions would solve the problems of farming households in the South:

- The Flemish government preferably buys Fair Trade products.

- For some agricultural products the EU pays an export subsidy.

- The problems of rural households in the South are included in secondary school teaching plans.
- Southern governments invest more in their agricultural sector.

- Southern governments invest more in schooling.

- Northern governments invest more in development cooperation aimed at agriculture, rural development and food security.

Next, the following business-oriented policy interventions were proposed to the respondent for scoring:

- subsidies for companies buying Fair Trade products;

- taxes on non-Fair Trade products;

- obligation for supermarkets to offer a certain amount of Fair Trade products;

- ceiling on supermarket profit margins for Fair Trade products.

Third, respondents had to rate whether a list of actors bear responsibility to tackle the problems of Southern farmers and to what extent these actors have the opportunity to contribute to solutions. The actors concerned include consumers in the North, citizens in the North, governments in the North, governments in the South, international institutions, NGOs, small-scale farmers in the South and supermarket chains (through their purchasing behaviour).

Next, we inquired about a set of dimensions of Fair Trade consumer behaviour following De Pelsmacker et al. (2005). Respondents were asked to rate to what extent a set of statements applied to them. These statements concerned knowledge, involvement, concern, credibility, consent, importance, trust, charity, colonialism, willingness to buy, attitude towards price, interest, observed effectiveness of consumption, knowledge of points of sale and observed accessibility.

A fifth set of questions related to Fair Trade buying behaviour. Respondents were asked to indicate how many times they bought products identified as Fair Trade, how much money they spent, and where they purchased these products.

A final set of questions inquired about the sociodemographic background of the respondents, including gender, age, place of residence, occupation or type of study and level of education. 
Table 1 Effect of framing on policy preferences and attribution of responsibility and opportunity to act for the entire sample

\begin{tabular}{|c|c|c|c|c|}
\hline & $\begin{array}{c}1 \\
\text { Retailer }\end{array}$ & $\begin{array}{c}2 \\
N G O\end{array}$ & $\begin{array}{c}3 \\
\text { Test }\end{array}$ & $\begin{array}{c}4 \\
\text { Control }\end{array}$ \\
\hline \multicolumn{5}{|l|}{ General policy interventions } \\
\hline Government purchase of Fair Trade products & $5.40^{4}$ & 5.37 & $5.39^{4}$ & 5.22 \\
\hline EU export subsidy for some products & $3.73^{2}$ & 3.54 & $3.82^{2}$ & $3.79^{2}$ \\
\hline Inclusion of Fair Trade theme in secondary school & $5.37^{4}$ & 5.25 & $5.35^{4}$ & 5.12 \\
\hline Southern governments invest more in agriculture & 5.21 & 5.16 & 5.25 & 5.11 \\
\hline Southern governments invest more in education & $5.82^{4}$ & 5.70 & $5.79^{4}$ & 5.60 \\
\hline Northern governments invest more in development cooperation & $5.46^{4}$ & 5.37 & $5.48^{4}$ & 5.33 \\
\hline \multicolumn{5}{|l|}{ Business-oriented interventions } \\
\hline Subsidies for companies buying Fair Trade products & 5.05 & 5.14 & $5.23^{1,4}$ & 5.04 \\
\hline Taxes on non-Fair Trade products & 3.99 & 4.03 & 4.10 & 3.92 \\
\hline Obligation for supermarkets to offer a certain amount of Fair Trade products & 3.93 & $4.43^{1}$ & $4.43^{1}$ & $4.31^{1}$ \\
\hline Ceiling on supermarket profit margins for Fair Trade products & 5.08 & $5.25^{4}$ & $5.38^{1,4}$ & 5.02 \\
\hline \multicolumn{5}{|l|}{ Attribution of responsibility } \\
\hline Individual consumers & 4.46 & 4.38 & $4.74^{2,1,4}$ & 4.45 \\
\hline Individual citizens & 3.91 & 3.95 & $4.12^{1,4,2}$ & 3.91 \\
\hline Northern governments & 5.44 & $5.61^{1}$ & $5.66^{1}$ & $5.65^{1}$ \\
\hline Southern governments & 5.67 & 5.71 & 5.64 & 5.72 \\
\hline International institutions & 5.91 & 5.98 & 5.91 & 5.97 \\
\hline NGOs & $5.35^{3}$ & $5.34^{3}$ & 5.17 & $5.35^{3}$ \\
\hline Southern farmers & $4.27^{2,3}$ & 3.94 & 4.06 & $4.37^{3,2}$ \\
\hline Supermarkets & 4.96 & 4.98 & $5.32^{1,2,4}$ & 5.07 \\
\hline \multicolumn{5}{|l|}{ Attribution of opportunity to act } \\
\hline Individual consumers & 4.53 & 4.47 & $4.71^{1,2,4}$ & 4.51 \\
\hline Individual citizens & 3.85 & $4.01^{1}$ & $4.07^{1,4}$ & 3.86 \\
\hline Northern governments & 5.76 & $5.91^{1}$ & $5.92^{1}$ & $5.91^{1}$ \\
\hline
\end{tabular}


Table 1 Continued

\begin{tabular}{|c|c|c|c|c|}
\hline & $\begin{array}{c}1 \\
\text { Retailer }\end{array}$ & $\stackrel{2}{\text { NGO }}$ & $\begin{array}{c}3 \\
\text { Test }\end{array}$ & $\begin{array}{c}4 \\
\text { Control }\end{array}$ \\
\hline Southern governments & 5.37 & 5.35 & 5.39 & $5.55^{1,3,2}$ \\
\hline International institutions & 5.94 & $6.09^{1,3}$ & 5.99 & $6.13^{1,3}$ \\
\hline NGOs & 5.40 & 5.41 & 5.33 & $5.45^{3}$ \\
\hline Southern farmers & $3.41^{3}$ & 3.36 & 3.22 & $3.52^{2,3}$ \\
\hline Supermarkets & 5.07 & 5.08 & $5.39^{1,2,4}$ & $5.25^{1,2}$ \\
\hline
\end{tabular}

Note: A number in superscript refers to whether there is a significant difference with that frame (significance at $p<0.10$ level). For example, superscript 2 in the fifth column (frame \#4) means that frame \#4 is significantly more effective than frame \#2.

Table 2 Effect of framing on policy preferences and attribution of responsibility and opportunity to act for the student subsample

\begin{tabular}{|c|c|c|c|c|}
\hline & $\begin{array}{c}1 \\
\text { Retailer }\end{array}$ & $\begin{array}{c}2 \\
\text { NGO }\end{array}$ & $\begin{array}{c}3 \\
\text { Test }\end{array}$ & $\begin{array}{c}4 \\
\text { Contro }\end{array}$ \\
\hline \multicolumn{5}{|l|}{ General policy interventions } \\
\hline Government purchase of Fair Trade products & 5.26 & 5.20 & $5.38^{4}$ & 5.10 \\
\hline EU export subsidy for some products & $3.83^{2}$ & 3.61 & 3.79 & $3.94^{2}$ \\
\hline Inclusion of fair trade theme in secondary school & 5.23 & 5.08 & $5.41^{2,4}$ & 5.13 \\
\hline Southern governments invest more in agriculture & 5.20 & 5.06 & $5.30^{2}$ & 5.13 \\
\hline Southern governments invest more in education & $5.81^{2,4}$ & 5.62 & $5.85^{2,4}$ & 5.58 \\
\hline Northern governments invest more in development cooperation & $5.44^{2}$ & 5.24 & $5.45^{2}$ & 5.40 \\
\hline \multicolumn{5}{|l|}{ Business-oriented interventions } \\
\hline Subsidies for companies buying Fair Trade products & 5.10 & 5.19 & $5.34^{1}$ & 5.23 \\
\hline Taxes on non-Fair Trade products & 3.95 & 4.05 & 4.15 & 4.02 \\
\hline Obligation for supermarkets to offer a certain amount of Fair Trade products & 3.83 & $4.39^{1}$ & $4.52^{1}$ & $4.42^{1}$ \\
\hline Ceiling on supermarket profit margins for Fair Trade products & 5.13 & 5.31 & $5.45^{1,4}$ & 5.15 \\
\hline \multicolumn{5}{|l|}{ Attribution of responsibility } \\
\hline Individual consumers & 4.30 & 4.27 & $4.67^{1,2,4}$ & $4.44^{2}$ \\
\hline Individual citizens & 3.71 & 3.88 & $3.97^{1}$ & 3.87 \\
\hline
\end{tabular}


Table 2 Continued

\begin{tabular}{|c|c|c|c|c|}
\hline & $\begin{array}{c}1 \\
\text { Retailer }\end{array}$ & $\stackrel{2}{N G O}$ & $\begin{array}{c}3 \\
\text { Test }\end{array}$ & $\begin{array}{c}4 \\
\text { Control }\end{array}$ \\
\hline Northern governments & 5.40 & 5.53 & $5.63^{1}$ & $5.64^{1}$ \\
\hline Southern governments & 5.71 & 5.70 & 5.58 & 5.67 \\
\hline International institutions & 5.83 & 5.90 & 5.84 & $5.97^{1}$ \\
\hline NGOs & 5.21 & 5.26 & 5.11 & $5.45^{1,3,2}$ \\
\hline Southern farmers & $4.24^{2,3}$ & 3.90 & 3.99 & $4.29^{2,3}$ \\
\hline Supermarkets & 4.86 & 4.92 & $5.21^{1,2,4}$ & $5.03^{1}$ \\
\hline \multicolumn{5}{|c|}{ Attribution of opportunity to act } \\
\hline Individual consumers & 4.44 & 4.40 & $4.70^{1,2,4}$ & 4.48 \\
\hline Individual citizens & 3.67 & $3.89^{1}$ & $4.04^{1,4}$ & 3.81 \\
\hline Northern governments & 5.75 & 5.86 & $5.90^{1}$ & $5.94^{1}$ \\
\hline Southern governments & 5.40 & 5.31 & 5.31 & 5.47 \\
\hline International institutions & 5.90 & 6.01 & 5.92 & $6.13^{1,3,2}$ \\
\hline NGOs & 5.34 & 5.37 & 5.32 & $5.54^{1,2,3}$ \\
\hline Southern farmers & $3.36^{3}$ & $3.32^{3}$ & 3.13 & $3.46^{3}$ \\
\hline Supermarkets & 4.93 & 5.01 & $5.31^{1,2}$ & $5.20^{1,2}$ \\
\hline
\end{tabular}

Note: A number in superscript refers to whether there is a significant difference with that frame (significance at $p<0.10$ level).

\section{Results}

In total 1617 questionnaires were completed. The youngest respondent was 15 years old, the oldest 78. The majority of the respondents were students (1084), such that the average age of the total sample is 24 , while the average age of the student subsample is 21 . To reflect this constituency bias, the results will be discussed for both the 'students only' sample $(n=1084)$ and the total sample $(n=1617)$. Women represented $63 \%$ of the sample; men only $37 \%$. Respondents originated from all over Flanders. Pearson Chi-square tests confirmed that there are no differences between the four groups in terms of gender, age, buying behaviour (buyers vs. non-buyers of Fair Trade products), point of purchase and being a student or not. This confirms that respondents were randomly assigned to each of the four groups. Cronbach's alpha confirmed the internal consistency and that correlations between the questions belonging to a construct were sufficiently high.

In Table 1 the average scores by frame are recorded for the entire sample for four constructs: attribution of responsibility, attribution of opportunity to act, general policy preferences and businessoriented policy preferences. Results for the student subsample are reported in Table 2 . The average scores by frame for the entire sample for the different dimensions of consumer attitude towards Fair Trade are reported in Table 3 and in Table 4 for the student subsample. All tables indicate whether averages differ between the frames in a statistically significant way. In what follows, we only report the results for the full sample. 
Table 3 Effect of framing on consumer attitude for the entire sample

\begin{tabular}{|c|c|c|c|c|}
\hline & $\begin{array}{c}1 \\
\text { Retailer }\end{array}$ & $\stackrel{2}{N G O}$ & $\begin{array}{c}3 \\
\text { Test }\end{array}$ & $\begin{array}{c}4 \\
\text { Control }\end{array}$ \\
\hline Knowledge & $5.55^{4}$ & $5.65^{4}$ & $5.69^{1,4}$ & 5.42 \\
\hline Involvedness & 4.76 & $5.02^{1,4}$ & $5.00^{1,4}$ & 4.86 \\
\hline Concern & 4.92 & 5.01 & $5.10^{1}$ & 4.99 \\
\hline Credibility & 5.92 & 6.01 & 6.00 & $6.05^{1}$ \\
\hline Consent & 6.04 & 6.07 & 6.14 & $6.15^{1}$ \\
\hline Confidence & 5.36 & 5.44 & $5.59^{1,2}$ & 5.47 \\
\hline Importance & 5.69 & 5.79 & $5.84^{1}$ & $5.86^{1}$ \\
\hline $\begin{array}{l}\text { Willingness to } \\
\text { buy }\end{array}$ & 4.27 & 4.40 & $4.61^{1,2}$ & $4.56^{1,2}$ \\
\hline $\begin{array}{l}\text { Attitude } \\
\text { towards price }\end{array}$ & 4.82 & 4.92 & $5.16^{1,2,4}$ & $5.00^{1}$ \\
\hline Interest & 4.54 & $4.74^{1}$ & $4.85^{1}$ & $4.86^{1}$ \\
\hline $\begin{array}{l}\text { Observed } \\
\text { effectiveness }\end{array}$ & 4.81 & 4.83 & $4.97^{1,2}$ & 4.86 \\
\hline Charity & 3.74 & 3.85 & 3.77 & 3.70 \\
\hline Colonialism & 2.15 & 2.14 & 2.18 & 2.16 \\
\hline $\begin{array}{l}\text { Knowledge of } \\
\text { outlets }\end{array}$ & 5.60 & $5.80^{1}$ & $5.83^{1}$ & $5.80^{1}$ \\
\hline $\begin{array}{l}\text { Observed } \\
\text { accessibility }\end{array}$ & $5.09^{2,3}$ & 4.85 & 4.78 & 4.95 \\
\hline
\end{tabular}

Note: A number in superscript refers to whether there is a significant difference with that frame (significance at $p<0.10$ level).

The test frame was the only frame that increased the responsibility of individuals both as consumers and as voters, and the responsibility of supermarkets. The NGO frame did not perform well overall. The retailer frame scored equally as well as the control group in assigning responsibility to farmers in the South. The test frame reduced support for NGOs and farmers in the South as responsible actors. So, to conclude, the test frame was successful in shifting responsibility from
Table 4 Effect of framing on consumer attitude for the student subsample

\begin{tabular}{|c|c|c|c|c|}
\hline & $\begin{array}{c}1 \\
\text { Retailer }\end{array}$ & $\stackrel{2}{N G O}$ & $\begin{array}{c}3 \\
\text { Test }\end{array}$ & $\begin{array}{c}4 \\
\text { Control }\end{array}$ \\
\hline Knowledge & $5.54^{4}$ & $5.61^{4}$ & $5.69^{1,4}$ & 5.42 \\
\hline Involvedness & 4.70 & $5.02^{1,4}$ & $4.96^{1,4}$ & 4.81 \\
\hline Concern & 4.85 & 4.97 & $5.03^{1}$ & 4.96 \\
\hline Credibility & 5.94 & 5.97 & 5.96 & 6.02 \\
\hline Consent & 6.01 & 5.98 & $6.13^{2}$ & $6.18^{1,2}$ \\
\hline Confidence & 5.32 & 5.31 & $5.55^{1,2}$ & $5.48^{1,2}$ \\
\hline Importance & 5.65 & 5.70 & $5.80^{1,2}$ & $5.83^{1,2}$ \\
\hline $\begin{array}{l}\text { Willingness to } \\
\text { buy }\end{array}$ & 4.07 & 4.23 & $4.49^{1,2}$ & $4.49^{1,2}$ \\
\hline $\begin{array}{l}\text { Attitude towards } \\
\text { price }\end{array}$ & 4.75 & 4.81 & $5.07^{1,2}$ & $4.96^{1,2}$ \\
\hline Interest & 4.42 & $4.66^{1}$ & $4.71^{1}$ & $4.82^{1}$ \\
\hline $\begin{array}{l}\text { Observed } \\
\text { effectiveness }\end{array}$ & 4.73 & 4.75 & $4.91^{1,2}$ & 4.83 \\
\hline Charity & 3.98 & 3.94 & 3.90 & 3.92 \\
\hline Colonialism & 2.16 & 2.13 & 2.19 & 2.17 \\
\hline $\begin{array}{l}\text { Knowledge of } \\
\text { outlets }\end{array}$ & 5.47 & $5.71^{1}$ & $5.76^{1}$ & $5.74^{1}$ \\
\hline $\begin{array}{l}\text { Observed } \\
\text { accessibility }\end{array}$ & $4.95^{3}$ & 4.83 & 4.73 & 4.90 \\
\hline
\end{tabular}

Note: A number in superscript refers to whether there is a significant difference with that frame (significance at $p<0.10$ level).

NGOs and farmers in the South to individuals and supermarkets in the North.

A similar picture emerges for the respondents' perception of actors' opportunity to act, that is, the test frame performed better than the control group in attributing opportunity to individual consumers, citizens and supermarkets. Moreover, the test frame also resulted in a significantly higher score than the retail score for the same actors and Northern governments. 
Both the test frame and the retailer frame scored significantly better than the control group for four out of six general policy preferences: government purchase of Fair Trade products, inclusion of Fair Trade theme in secondary school, more government investment in education in the South, and more government investment in development cooperation by the North. The NGO frame scored worse than the control group for the EU export subsidy.

The test frame scored significantly better than the control group for two out of four policy interventions targeted at businesses, that is, the subsidies for firms buying Fair Trade products and the ceiling on higher profit margins on Fair Trade labelled products. For the latter, the NGO frame also raised significantly more support than the control group. The retailer frame was unable to increase support for any of the four interventions.

Finally, with respect to the dimensions of consumer attitude towards Fair Trade, the test frame scored better than the control group on only three dimensions: knowledge, involvedness and attitude towards price. In fact all frames performed better than the control group for knowledge. Willingness to pay was best represented by both the test and the control frame, which means that both retailers and NGOs are ineffective communicators for promoting Fair Trade purchasing behaviour. The retail frame scores in particular were bad on many dimensions, such as confidence, importance, interests and even knowledge of outlets. However, the retail frame increased observed accessibility of Fair Trade products compared to the NGO frame and the test frame.

In summary, the test frame performs well in shifting attention towards the individual as an actor of change, but particularly as a citizen, less so as a consumer. The implication for communication that addresses behavioural change is that it should address individuals as citizens rather than as consumers. These results are consistent with the earlier findings of Aubrun et al. (2006).

\section{Summary and conclusions}

This paper has investigated whether reframing Fair Trade in a communication message can change individuals' attitude towards Fair Trade. Using an internet-based experimental setup, individuals were exposed to an NGO-based frame, a retailerbased frame, an experimental frame or no frame. Statistical analysis then indicated whether the experimental frame performed better than the control group and the other frames in shifting people's attitudes. Our results suggest that a brief exposure to a combination of tone, messenger, value and metaphor that signals the systemic aspects of Fair Trade may be successful in shifting the attitude and opinion of Flemish consumers/ citizens in favour of Fair Trade. NGO- and retailer-based communications are often counterproductive.

Our observations support the hypothesis that reframing Fair Trade using message elements that better communicate the systemic aspects of Fair Trade results in a more positive attitude towards Fair Trade compared to the dominant discourse and rhetoric used by NGOs and retailers in the context of Flemish culture. However, as the effect we have measured is only valid in the short term and as we only measured changes in attitudes, we cannot conclude that reframing by itself has the capacity to change generally held mental models and worldviews. We do suggest that reframing messages related to food may be the trigger that can set in motion the process of reflexivity that is needed for sustained change in food consumption. For dominant discourse about food and sustainability to change, such reframing should be a sustained effort by actors seeking to increase the sustainability of the agricultural and food system.

Our analysis suggests that the foundations metaphor that has been developed in the context of the environmental impact of food production can also be applied in the context of the social impact of food production. In addition, reframing seems to be more effective as a dimension in changing an individual's attitude as a citizen rather than as a consumer, which is an important result to be taken into consideration by communication campaigns aimed at changing consumer behaviour. In other words, when organizations want to change food consumption towards more sustainability, they should take into consideration two recommendations. First, they should not address the public as a consumer, as that would reinforce current, dominant frames about food consumption. Rather, they should use communication 
strategies aimed at addressing the public as an actor that can influence the behaviour of business and government in a democratic way. Second, they should not focus only on a single aspect when reporting an issue (e.g. worker health), but they should also explain how that aspect fits in the larger agricultural and food system.

\section{Acknowledgements}

The authors gratefully acknowledge the comments of three anonymous referees and the valuable contributions of Mieke Lateir, Chris Claes, Jo Vermeersch and Nele Claeys of Vredeseilanden, and Koen De Maesschalck, Sandra Michiels, Lisa Colruyt and Stefanie Van Den Bossche of Colruyt. This work has been inspired by the Framing Research undertaken in the framework of the Sustainable Food Lab and financed by the W. K. Kellogg Foundation and the King Baudouin Foundation.

\section{References}

Aubrun, A. and Grady, J.E. (2006) Towards a CrossCultural Simplifying Model for Food Systems: Findings from French Talkback Research. Brussels: Cultural Logic for the The King Baudouin Foundation.

Aubrun, A., Brown, A. and Grady, J.E. (2005) Not While I'm Eating: How and Why Americans Don't Think about Food Systems. Washington, DC: Cultural Logic for the FrameWorks Institute.

Aubrun, A., Brown, A. and Grady, J.E. (2006) Conceptualizing US Food Systems with Simplifying Models: Findings from the TalkBack Testing. Washington, DC: Cultural Logic for the FrameWorks Institute.

Aubrun, A., Brown, A. and Grady, J.E. (2007) Towards a Cross-Cultural Simplifying Model for Food Systems. Supplemental Memo: Findings from TalkBack Research in the United Kingdom. Brussels: Cultural Logic for the The King Baudouin Foundation.

Bales, S.N. (2002) Framing Public Issues. Washington, DC: FrameWorks Institute, p. 60.

Bartlett, F.C. (1932) Remembering: A Study in Experimental and Social Psychology. Cambridge, UK: Cambridge University Press.

Bateson, G. (1972) Steps to an Ecology of Mind. New York: Ballentine Books.

Bawden, R.J. (2005) Systemic development at Hawkesbury: some personal lessons from experience. Systems Research and Behavioral Science 22, 151-164.
Cox, R. (2006) Environmental Communication and the Public Sphere. Thousand Oaks, CA: Sage.

De Pelsmacker, P., Janssens, W. and Mielants, C. (2005) Consumer values and fair-trade beliefs, attitudes and buying behaviour. International Review on Public and Non Profit Marketing 2 (2), 50-69.

FrameWorks Institute (2007) The FrameWorks Institute. On WWW at http://www.frameworksinstitute.org/. Accessed 07.05.07.

Giddens, A. (1984) The Constitution of Society: Outline of the Theory of Structuration. Cambridge: Polity.

Gilliam, F.D., Jr. and Bales, S.N. (2002) Strategic frame analysis and youth development: how communications research engages the public. In: R.M. Lerner, F. Jacobs and D. Wertlieb (eds) Handbook of Applied Developmental Science: Applying Developmental Science for Youth and Families: Historical and Theoretical Foundations. Thousand Oaks, CA: Sage.

Goffman, E. (1974) Frame Analysis: An Essay on the Organization of Experience. London: Harper and Row.

Goffman, E. (1981) A reply to Denzin and Keller. Contemporary Sociology 10 (1), 60-68.

Habermas, J. (1970) Knowledge and interest. In: D. Emmet and A. MacIntyre (eds) Sociological Theory and Philosophical Analysis. London: MacMillan.

IDEA Consult (2007) Marktstudie Eerlijke Handel in België 2006. Brussels: IDEA Consult.

Iyengar, S. (1991) Is Anyone Responsible? How Television Frames Political Issues. Chicago, IL: University of Chicago Press.

Jackson, T. (2005) Motivating Sustainable Consumption: A Review of Evidence on Consumer Behaviour and Behavioural Change. London: Policy Studies Institute.

Kaplan, S. and Kaplan, R. (1982) Cognition and Environment: Functioning in an Uncertain World. New York: Praeger Publishers.

Kuhn, T. (1962) The Structure of Scientific Revolutions. Chicago, IL: University of Chicago Press.

Lippmann, W. (1921) Public Opinion. New York: The Free Press.

Mebratu, D. (1998) Sustainability and sustainable development: historical and conceptual review. Environmental Impact Assessment Review 18, 493-520.

Raynolds, L.T. (2000) Re-embedding global agriculture: the international organic and fair trade movements. Agriculture and Human Values 17, 297-309.

Solomon, M., Bamossy, G., Askegaard, S. and Hogg, M.K. (2006) Consumer Behaviour: A European Perspective. Harlow, UK: Prentice Hall.

Strong, C. (1998) The role of fair trade principles in sustainable development. Sustainable Development 5 (1), $1-10$.

van Calker, K.J., Berentsen, P.B.M., Romero, C., Giesen, G.W.J. and Huirne, R.B.M. (2006) Development and application of a multi-attribute sustainability function 
for Dutch dairy farming systems. Ecological Economics 57 (4), 640-658.

Van Cauwenbergh, N., Biala, K., Bielders, C., Brouckaert, V., Franchois, L., Garcia Cidad, V., Hermy, M., Mathijs, E., Muys, B., Reijnders, J., Sauvenier, X., Valckx, J., Vanclooster, M., Van der Veken, B., Wauters, E. and Peeters, A. (2007) SAFE a hierarchical framework for assessing the sustainability of agricultural systems. Agriculture, Ecosystems and Environment 120 (2-4), 229-242.

Van Gorp, B. (2007) The constructionist approach to framing: bringing culture back in. Journal of Communication $57,60-78$.

Vermeir, I. and Verbeke, W. (2006) Sustainable food consumption: exploring the consumer 'attitude-behavioral intention' gap. Journal of Agricultural and Environmental Ethics 19 (2), 169-194.

Yankelovich, D. (1991) Coming to Public Judgement: Making Democracy Work in a Complex World. Syracuse, NY: Syracuse University Press.

\section{Appendix 1: alternative frames}

\section{Retailer message}

Increasingly, some retailers have the intention to take up responsibility in society. Aside from offering high quality products, safe transport and good service they now also engage to achieve a respectful trade relation with actors in the countries or regions in economic development. In this way, they want to contribute to development and welfare in these regions. By selling Fair Trade products in their outlets, retailers want to offer small family farmers in countries or regions of economic development a larger outlet. These farmers receive a fixed price for their product, which gives them the opportunity to strengthen their organization and improve the quality of their products. In this way they can eventually be independent and contribute to the development of their country. Consumers can support them by buying Fair Trade products.

\section{NGO message}

Some NGOs (Non-Governmental Organizations) that are occupied with the problems of small male and female family farmers in the South focus their attention on the unfairness in international trade relations. More than 850 million people or one-seventh of the world population suffers from hunger and a large proportion of them are farmers. That's why these NGOs want to guarantee a fair income to farm families in the South in exchange for their labour and that's why these NGOs support them in their struggle against hunger and poverty. The international development, trade and agricultural policy is to blame for this inequality. Farming families in the South often have to deal with weak governments in a wild, capitalist context, dominated by large food companies. The latter do not pay attention to the farmers or their income. Because farmers do not have means of their own, they cannot find their place on the harsh world market. In addition, their own markets are being flooded by other countries that dump their production surpluses, often stimulated by generous export subsidies. Fair Trade aids small farmers to unite and to make their voice louder, which protects them against economic abuse. By buying Fair Trade products consumers in the North give a clear signal to retailers and governments in North and South: international trade can and has to be different.

\section{Test message}

Scientists are increasingly worried about the fact that not everyone can enjoy the benefits of globalization. The inequality in international trade relations is a threat to the foundations of our food system. Experts therefore wonder whether this is the inheritance we want to leave to future generations. They contend that Fair Trade products can contribute to solving this problem. As a result of the purchasing policy of retailers and the government policies in North and South, farming families in the South have limited access to international markets. They hence cannot improve their situation, while poverty and inequality is a continuous source of tensions throughout the world. In addition, the socio-economic base of whole regions and countries is brought off balance by the influence large multinationals exert on the food supply chain. They increasingly use intensive and industrial technologies to produce food, causing a huge increase in scale at the expense of small-scale family farms. Those who buy Fair Trade products show that everyone should enjoy the benefits of globalization. In that sense, these products are a signal from concerned consumers who do not want the foundations of our food system being endangered. In this way, they support a vision that takes into account long-term consequences. 